\title{
Amniotic Band Syndrome: An Unusual Presentation
}

\author{
Vidhi Sahni ${ }^{1}$, Chandni Sharma ${ }^{2}$,Deepak Sharma ${ }^{3}$
}

\begin{abstract}
Amniotic band syndrome (ABS) is a set of congenital malformations attributed toamniotic bands that entangle fetal parts during intrauterine life, which results in a broad spectrum of anatomic disturbances ranging from minor constriction rings and lymphedema of the digits to complex, bizarre multiple congenital anomalies incompatible with life. ABS should be considered in every newborn with congenital anomalies, especially defects of extremities and/or body walls. ABS can be diagnosed prenatally by ultrasound; otherwise, the defects are seen after birth. Child's karyotyping is

of great importance, in order to avoid misdiagnosis and incorrect information of recurrence risk. A team of specialists should be included in the treatment and follow-up of children with ABS, according to individual needs of every single patient.
\end{abstract}

Keywords: amniotic band syndrome, ultrasound, karyotyping.

\section{Introduction}

Amniotic band syndrome (ABS) is a rare congenital disorder caused by entrapment of fetal parts by fibrous amniotic bands, resulting in devastating cosmetic and functional disability ranging from minorconstriction rings and lymphedema of the digitsto complex, bizarre multiple congenital anomalies incompatible with life. ${ }^{1}$ Its Incidence varies from 1:1200 - 1:15000 live births. ${ }^{2,3}$ Among total of 3\%major malformations in general population ${ }^{4} \mathrm{ABS}$ is responsible for $1-2 \%{ }^{5}$ The aim of this discussion is to identify this unusual presentation in newborns through two case scenarios .

\section{Case report no 1}

A $3 \mathrm{~kg}$ fullterm newborn was delivered to a 28 year female, 3 years after a previous normal baby. Pregnancy was regularly controlled, had favourable course with no history of drug exposure ,consanguity, family history of congenital defects. Ultrasound examination did not show any fetal malformations. Delivery occurred in $38{ }^{1 / 7}$ gestational week, birth weight was $2880 \mathrm{~g}$, birth length $50 \mathrm{~cm}$, head circumference $33 \mathrm{~cm}$, Apgar score $9 / 10$. The baby was born with the following malformations:

1. Left hand with two middle fingers deformed .

2. Right hand with rudimentary first three fingers.

3. Fibrous band seen at junction of right foot and leg.

4. Lymphedema of right foot.

5. Hypertelorism, flat nasal bridge, thin lips, malposition of the ears.Karyotype was normal female (46, XX). All systemic investigations including ultrasound of skull and abdominal organs, echocardiographyand ophthalmoscopic examination showed normal anatomy of the examined organs.

1. Senior Resident (Pediatrics), Kalpana Chawla Govt. Medical College, Karnal, Haryana.

2. Assistant Professor (ENT), PGIMS Rohtak, Haryana.

3. Consultant Neonatologist, Neoclinic,Jaipur, Rajasthan.

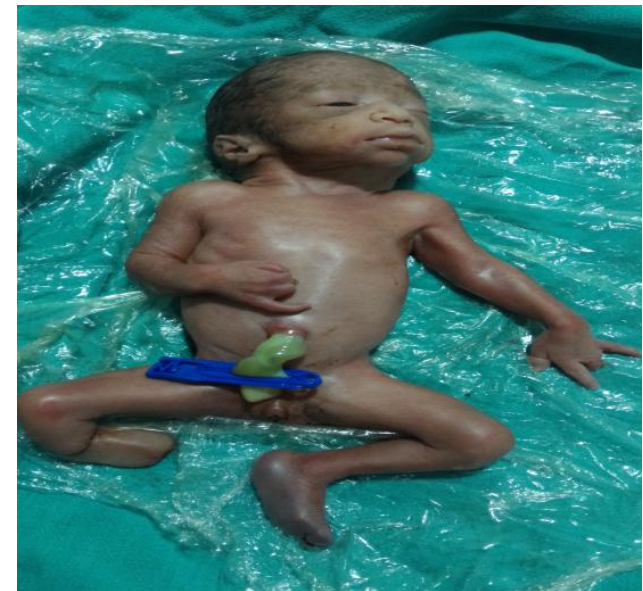

Figure 1 newborn with ABS 


\section{Case report 2}

Another case with a different presentation was born to 30 year old mother born after37 gestational weeks as a first child from a regularly controlled pregnancy .Trauma during pregnancy, prenatal fetal karyotyping, circlage, teratogenic drug intake, consanguinity or congenital anatomicalmalformations in family were denied. Routine ultrasound examination did not show any fetal malformations. Birth weight was 2650 grams , birth length $56 \mathrm{cms}$, head circumference $32 \mathrm{cms}$, Apgar score 8/9. Immediately after birth, the following malformations wereobserved:

1. Amniotic band mark on the upper part of the right foot

2. Syndactyly of II and III, and IV and V right toes; right toes were shortened with hypoplastic nails on the right foot.

3. Amniotic band mark seen at the junction of chest and abdomen (which is not so commonly observed in this syndrome)

4. Asymmetric and malformed ears, funnel like bended thoracic cage, bilateral clinodactylyof the fifth finger, sandal creases on the feet.

Karyotype was normal male (46, XY). All performed examinations (ultrasound of skull and abdominal organs, echocardiography, ophtalmoscopic examination) showed normal anatomy of examined organs.

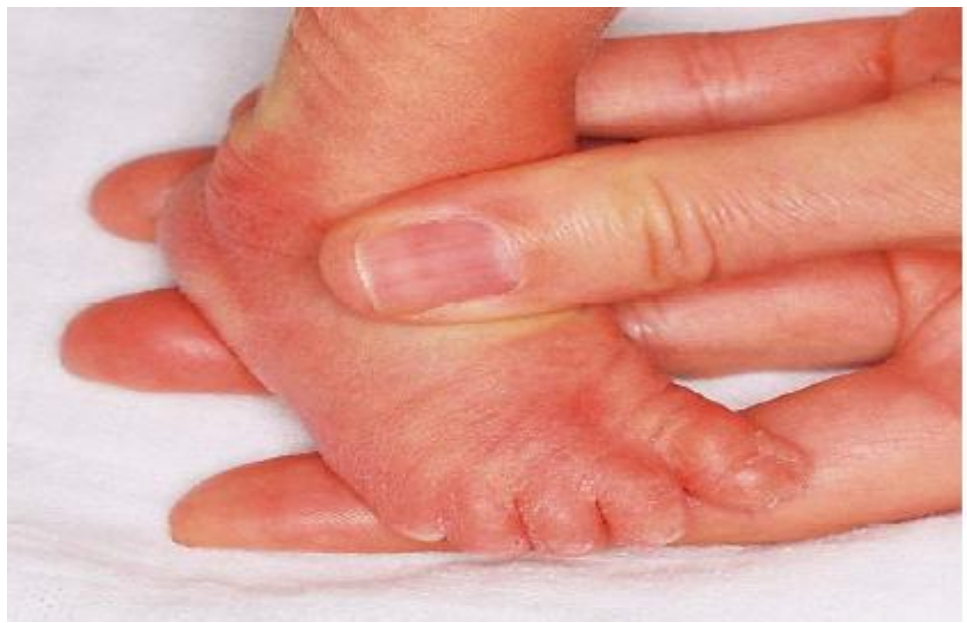

Figure 2 Right foot deformities

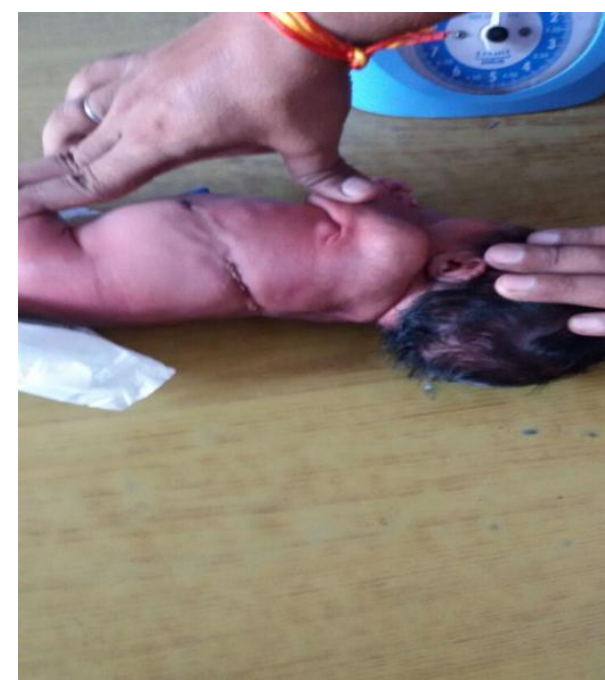

Figure 3 newborn with amniotic band mark .

\section{Discussion}

ABS diagnosed in early pregnancy can be a sporadic event with no exceptional history. The most accepted etiology for ABS is the one proposed by Tropin. ${ }^{6}$ He proposed that disruption of the amnion initiates a cascade of secondary events that cause ABS. Amniotic rupture occurring early in gestation can cause multiple malformations, 
whereas, rupture occurring later causes limb anomalies. ${ }^{7} \mathrm{ABS}$ can be diagnosed as early as 12 weeks by ultrasound, which may show amniotic bands, often malformations consistent with ABS, as well as oligohydramnios and reduction of foetal movements. ${ }^{8}$ The most important ultrasounddiagnostic criteria are visible amniotic bands, constriction rings on extremities and irregular amputations of fingers and/or toes with terminal syndactyly.Placenta and amnion should be examined for the presence of amniotic band. ${ }^{2,9,10}$ Therapy of ABS is mostly surgical, with an individual approach to every single case. Multidisciplinary approach involving plastic surgeon, orthopedic surgeon, orthodontist,ophthalmologist, neurosurgeon is required. ${ }^{11}$ Now a days accepted modality of treatment of ABS is in utero fetoscopic laser surgery before the bands can compress fetal parts.

\section{Conclusion}

The basis for postnatal diagnosis is physical examination of the newborn, with additional examinations after potential internal organs malformations. Child's chromosomal karyotype analyses in order to exclude wrong diagnosis and consecutive incorrect information about recurrence risk for the parents is of outmost importance. Because of ABS complexity, the treatment and follow-up of these children requires a team of specialist, according to special needs of every patient.

\section{References}

[1]. Nardozza LMM, Araujo E, Caetano ACR, Moron AF. Prenatal Diagnosis of Amniotic Band Syndrome in the Third Trimester of Pregnancy using 3D Ultrasound. J Clin Imaging Sci [Internet]. India: Medknow Publications \& Media Pvt Ltd; $2012 ; 2: 22$.

[2]. Merrimen JL, McNeely PD, Bendor-Samuel RL, Schmidt MH, Fraser RB. Congenital placental-cerebral adhesion: an unusual case of amniotic band sequence.

[3]. J Neurosurg 2006; 104(5 Suppl): 352-5

[4]. KutluDilek TU, Yazici G, Gulhan S, Polat A, DilekB,Dilek S. Amniotic Band Syndrome Associated With Cranial Defects and EctopiaCordis: A Report of Two

[5]. Cases. J Turkish German GynecolAssoc 2005;6(4):308-10.

[6]. Brent RL. Environmental Causes of Human Congenital Malformations: The Pediatrician's Role in Dealing With These Complex Clinical Problems Caused by a

[7]. Multiplicity of Environmental and Genetic Factors.Pediatrics 2004;113(4 Suppl):957-68.

[8]. Martínez-Frías ML. Epidemiological characteristics of amniotic band sequence (ABS) and body wall complex (BWC): are they two different entities? Am J Med Genet 1997;73(2):176-9.

[9]. Torpin R. Amniochorionicmesoblastic fibrous strings and amniotic bands: Associated constricting fetal malformations or fetal death. Am J ObstetGynaecol 1965;91:65-75.

[10]. Seeds JW, Cefalo RC, Herbert WNP. Amniotic band syndrome.AmJ ObstetGynecol 1982;144:43-8.

[11]. Allen LM. Constriction Rings and Congenital Amputations of the Fingers and Toes in a Mild Case of Amniotic Band Syndrome. Journal of Diagnostic Medical Sonography 2007;23:280-5.

[12]. Ferns S, Sharma R, Narayanan P, Bhat BV. Limb Amputation DefectsIn Utero-A Case Report. J AnatSoc India 2001;50(2):156-8.

[13]. Bower C, Norwood F, Knowles S. Amniotic band syndrome: a population-based study in two Australian states. Paediatric and Perinatal Epidemiology 1993;7(4):395-403.

[14]. Poeuf B, Samson P, Magalon G. Amniotic band syndrome. Chir Main 2008;27(Suppl1):S136-47. 